\title{
Local Action for Realizing Sustainable Society: A Survey of Japanese "Futurecity" Initiative
}

\author{
Marina Takeyasu1, Haisong $\mathrm{Nie}^{1}{ }^{*}$, Dawei Gao ${ }^{2}$, Chuangbin Chen ${ }^{1}$ \\ ${ }^{1}$ Department of International Environmental and Agricultural Science, University of Agriculture and \\ Technology, 3-5-8 Saiwai-cho, Fuchu, Tokyo, Japan \\ 2 College of Economics and Management, Zhengzhou University of Light Industry, Henan 45003, China \\ * Corresponding author's e-mail: nie-hs@cc.tuat.ac.jp
}

How to Cite: Takeyasu, M., Nie, H., Gao, D., Chen, C. (2018). Local Action for Realizing Sustainable Society: A Survey of Japanese "Futurecity" Initiative. Int. J. Agr. Syst. 6(2): 130-137

\begin{abstract}
To convert a society to a sustainable system, attempts are required not only at international and governmental levels, but also at regional levels. It is necessary to challenge multiple issues through cooperation among various actors, such as national governments, local governments, private enterprises and residents. In Japan, one of the initiatives to achieve "the sustainable" at regional level is the "FutureCity" initiative. This is a part of National Strategic Projects in "New Growth Strategy", which Japanese government introduced in 2010. The purpose of the "Futurecity" initiative is to create the capacity in cities to deal with environmental issues and problems of aging society, as well as establishing sustainable socioeconomic system with environmental aspects, social aspects and economic aspects. Japanese government selected, as the "FutureCity", the five cities (Yokohama city, Shimokawa town, Kashiwa city, Toyama city and Kitakyusyu city) for making pioneering effort on these challenges, and the six cities that were hit by the Great East Japan Earthquake and great Tsunami in 2011. This "Future city" is expected to provide model solution of human common issues as a forerunner. The object of this research is to define the current situations and problems of the "FutureCity" initiative, through a case study on Yokohama city in Kanagawa prefecture, which is characterized as a big city in Japan. Here, we examined how Yokohama city is tackling the environmental issues and problems of aging society as the "FutureCity" and what problems it has in maintaining their initiative itself as a local government. In addition, we considered how, at international level, Japanese "FutureCity" initiative can contribute to realizing sustainable society.
\end{abstract}

Copyright @2018 IJAS. All rights reserved.

Keywords:

Futurecity; Sustainable Society; Aging Society; Environmental Issue

\section{Introduction}

The "FutureCity" Initiative is a part of National Strategic Projects in Japanese "New Growth Strategy", which is passed at a cabinet meeting on June 18, 2010. Presently, environmental issues and the aging problem are common concerns of the world. The purpose of the "FutureCity" initiative is to create the capacity in cities to deal with environmental issues and problems of aging society. Related papers and articles on this Initiative just consider it as a case to achieve "the sustainable" in Japan and few of them compare the actual situation of "FutureCity" with the implementation situation 
of related measures. On this basis, the objective of this paper is to research national policies on the "FutureCity" Initiative and the implementation situation of a local government and thereby define the current situation of the Initiative. Besides, among the 11 cities selected as "FutureCity", this research takes Yokohama City (an autonomous city) of Kanagawa Prefecture as an object of the study. This research is a case study of Yokohama City. Among the cities selected as "FutureCity", Yokohama City is characterized as a big city in Japan and adopts balanced measures to deal with problems which it is facing.

The "FutureCity" Initiative aims to solve the environmental and aging problems, help cities to create a new people-oriented value and create a successful case associated with technology, socioeconomic system, services, business models and city planning. Once achieved, this initiative is expected to be promoted and introduced to other cities and regions both within Japan and abroad. The basic concept of "FutureCity" is to achieve a city where "everyone wants to live" and "everyone has vitality" developing a sustainable economic society by creating environmental, economic and social values. In December 2011, the resolution approved by the Prime Minister determined that 11 cities in Japan, including Yokohama City, were selected as "FutureCity". The area, population, industries and geographic features selected autonomous cities are totally different. Each "FutureCity" adopts original measures to tackle regional issues which they are facing such as environmental problems like resources crisis, the regional social problems like declined birth rate and aging and the regional economic problems like vitality stimulation. They made their own "FutureCity" plans and take detailed measures. The object of this research is to define the current situations and problems of the "FutureCity" initiative, through a case study on Yokohama city in Kanagawa prefecture, which is characterized as a big city in Japan

\section{Method}

This research adopts three major research methods: material reference, onsite visit and interview and attending related conferences. This research analyzes materials, which is related to this Initiative, disclosed by the cabinet and Yokohama City as for the literature search part. On this basis, the author interviewed related officials at FutureCity Promotion Division of Yokohama City on July 6, 2017 and also attended the 7th International Forum on the "FutureCity" Initiative held by the Japanese Cabinet and Promotion Council for the "FutureCity" Initiative on October 4, 2017.

\section{Results and Discussion}

\subsection{Aim of the initiative as a national project}

According to the results of material reference, the purpose of taking the "FutureCity" Initiative as a national project is to stimulate the national vitality of Japan and promote advanced Japanese measures abroad. The author consults the following 2 documents publicly disclosed by the Japanese government.; first, New Growth Strategy (Decision by the Cabinet on June 18, 2010), and second, Medium-term Report on the "FutureCity" Initiative.

\subsubsection{Stimulation of the regional and national vitality of Japan}

The "FutureCity" Initiative aims to creative sustainable cities in Japan, taking "FutureCity" as a place where policies can be implemented and is devoted to the stimulation and development of national vitality of Japan starting from cities/regions. 
This initiative is a part of "the 21 National Strategic Projects for the Rebirth of Japan in the $21^{\text {st }}$ Century2 in the "New Growth Strategy". As for the selection of the above national strategic projects, the statement on " 21 Political Strategies with the Highest Contribution to Economic Growth" can be deemed that the government hopes to seek for Japanese economic growth through this initiative.

Besides, the Medium-term Report on the "FutureCity" Initiative puts forward that nowadays the problems of population decline, fertility decline, aging, disintegration of regional communities, and loss of social solidarity consciousness, environment and resources must be faced and dealt with by Japanese cities/regions. On this basis, in order to deal with environmental and aging problems and other issues with global concerns, we have to change the social economic system and the "FutureCity" is stimulating municipal and regional vitality by creating a place where related measures can be implemented, so that great contribution can be made to the development of Japanese economic society. In addition, the Initiative can also be deemed as a concrete methodology of the "New Growth Strategy" whose aim is to restore regional communities and create a sustainable economic society which can provide rich life for people. With regard to the national project of "FutureCity" Initiative, policies of the cabinet government centers on improving people's life quality and creating a practical place transforming towards a sustainable economic society, so as to deal with environmental and aging problems and other problems faced by cities/regions, stimulate vitality in related regions and realize the growth of Japanese economy.

\subsubsection{Exporting metropolitan policy package}

In the "FutureCity" Initiative, the second national policy is a typical example which exports the initiative as a Japanese metropolitan policy. The Chapter 3 - Surrounding Situation of Cities and Regions in the Medium-term Report on the "FutureCity" Initiative puts forward that one of the strengths of Japan lies in overcoming the harmful problems and the environmental and resources fields endangered by oil crisis and that Japanese environment-symbiotic technology is largely applied to Asian countries with sustainable growth. Besides, in Article (3) "conditions of overseas countries" of the same chapter makes a point that Japan is a pioneering nation with regard to the aging issue and other Asian countries will also face the same problem. Therefore, in competition with other countries, Japan takes the lead in proposing a social economic model dealing with Japanese super aging problem, which will become a big business opportunity in future. This project also mentions the following: Sweden, Denmark and other countries export their series of means of creating eco-city to overseas countries; Singapore obtained a business opportunity in China by participating in Tianjin's construction of eco-city; Japan joins overseas eco-city construction only on private enterprise levels. What's more, Article 2. "FutureCity Initiative" of Chapter 3 in the "New Growth Strategy" records that "unifying export of the whole city, promoting cooperation with Asian governments". To sum up, the "FutureCity" Initiative aims to promote the environmental technology owned by FutureCity or the successful case or urban policy dealing with the aging problem to overseas countries, stimulating domestic economy while making international contributions. It can be said that FutureCity is positioned to be a unified export of Japan cities. 


\subsection{Effective utilization of SDGs}

In order to investigate the state purpose closer to current situations, the author attended the 7th International Forum on the "FutureCity" Initiative hosted by the cabinet. Consequently, it was revealed that the guideline of the Initiative is to effectively utilize the sustainable development goals (SDGs) in future. The International Forum on the "FutureCity" Initiative is an international forum hosted by the cabinet, inviting representatives on behalf of their cities or renowned people both at home and abroad to make speeches and discuss the actual achievements or environmental problems, aging problem and other issues existed in autonomous cities after adopting related measures of the Initiative.

In order to promote the implementation of 2030 Agenda (with contents of SDGs) in Japan, the government set up a Promotion Head Office in May 2016 with Prime Minister Shinzo Abe as the highest leader. One of its concrete measures is to add contents to promote the "FutureCity" Initiative. As the internationalized structure, SDGs serve as comprehensive goals in the aspects of environment, society and economy, and the basic concept of FutureCity is interlinked with the achievements in the aspects of environment, society and economy. Therefore, there is high affinity between the above two factors. It can be said that, centering on the goal 11, there are various interlinks between the administration of autonomous cities and the SDGs. This forum hopes to draw up an independent executive program of SDGs and actively adopt SDGs measures in FutureCity. The above-mentioned points imply that the state will promote the development of SDGs in the level of autonomous cities and develop the "FutureCity" as a political strategy into SDGs future city (tentative).

Besides, the forum also discussed the significance of effective application of SDGs into FutureCity, that is, it is possible to promote the regional revitalization. Currently, Japan is facing population decline and regional recession. Regional revitalization has to deal with issues of various aspects, such as fertility decline, aging, environmental problem, rebirth of communities and so on. The foothold for the development of SDGs is to reflect the goals of SDGs in every program of autonomous cities. In addition, SDGs is a universal language. As for creating a successful case of FutureCity, the use of the international structure of SDGs subjects to global standard and can be promoted to every country. Effectively applying SDGs in the level of autonomous cities implies the possibility to encourage policies of regional revitalization and promote FutureCity internationally and make international contributions.

\subsection{Actual execution situation of "FutureCity" of Yokohama City}

The "FutureCity" Initiative is a national project, but its core dominant powers are all selected cities, that is local autonomous cities. This research is actually a case study, taking Yokohama City among the 11 selected cities as example to investigate its actual execution situation.

\subsubsection{Literature Research}

Yokohama City is located at east of Kanagawa Prefecture, south of Kanto, with a population of around 3.73 million and an area of about 435 kilometers. The current proportion of aged population is $24.0 \%$. In 2011, the city was selected to be FutureCity; in April 2012, the city made a "Yokohama FutureCity Plan-OPEN YOKOHAMA". Yokohama City adopts 42 measures in the following fields: "Environment 1: low carbon, energy conservation; Environment 2: water, natural environment; dealing with 
the super aging problem; others", see the Proposal for detailed information. What's more, the Proposal records index evaluation, numerical targets and policies of the above-mentioned fields and evaluation index, target value and schedule of every measure. The annual evaluation results on the progress of all measures are published in the "Evaluation Table of FutureCity Measures". As for all target values, the degree of completion based on independent evaluation has go graphic, and the average rate of target completion of Yokohama City in 2016 was 125.7\%.

\subsubsection{Visit and interviews}

Based on analysis on public materials of Yokohama City, the author conducted on-site visit and interviews in order to better grasp the actual implementation situation of FutureCity program. Coordinating Head Office of Global Warming of Yokohama City set up the FutureCity Promotion Division. The author visited and interviewed the division and summarized the results from the three aspects of program operation system, situation of measures implementation and future guidelines.

\section{a). Program operation system}

Yokohama City has taken many measures, attempting to improve people's life quality. As a result, the Yokohama FutureCity Plan was proposed. Although there are 42 measures in the proposal, these measures are implemented not as the national project of "FutureCity", but in as a program of Yokohama City. Although these measures involve many administrative agencies of Yokohama City, the tasks of this program are not assigned to these administrative agencies. Actually, these agencies independently or jointly act and complete their tasks in the name of FutureCity. Besides, the state does not provide funds to the program and all the causes mainly rely on tax revenue. Yokohama City applies for national financial aids for each measure. Therefore, Yokohama city is tackling issues which it is facing not as a "FutureCity" but as a local government.

\section{b) Measures with characteristics}

As for the three measures with characteristics in the aspect of target completion among the 42 measures of "Yokohama City FutureCity Program", the author summarizes the investigation results as follows:

- Y-PORT Project

"Measure 8: relying on citizen cooperation, providing support for emerging countries to solve problems" is a measure with the highest target completion rate (600\%) in 2016. The reason is that, in Measure 8 includes Y-PORT Project, which is an international technical corporation project with a public private partnership. In the Y-PORT cause, as for the issue of rapid urbanization and population growth for emerging countries, Yokohama City conducted international cooperation by effectively applying its own knowledge on urban construction (and environment) and environmental technology of enterprises, etc. The number of countries participating in international cooperation of the Y-PORT cause surpassed the previously settled target, thus improved the completion rate. Yokohama City mainly seeks for international cooperation in the field of "environmental technology". 


\section{- Yokohama Walking Point Project}

The countermeasure to deal with the aging problem is "Measure 14: establish relationship with people around you and create a structure of mutual assistance - the activity implementation of the aged in Yokohama City. Measure 14 had a 100\% target completion rate in 2016. In Measure 14, "promotion cause of Yokohama health lifestyle (Yokohama walking point)" means that citizens walk with pedometers and get scores according to their step numbers. The cause aims to promote citizens' health and preventive nursing for the aged, which has received high evaluation of domestic and international cities.

- Super-miniature mobility Project

"Measure 25: patiently strengthening the traffic convenience for citizens - verifying the use, popularization and promotion of super-miniature mobility" has a lower target completion rate. In 2016, the target completion rate of Measure 25 is $41 \%$. Superminiature mobility refers to the mobility of super-miniature electromobiles with two seats. Based on the features of such electromobiles, this new-type transportation vehicle is expected to satisfy social demands, such as forming a low carbon society and ensuring the travelling of the aged, etc. Nowadays, personnel related are conducting empirical study in specific regions of the city. But, electromobiles are neither light-duty vehicles nor regular motor vehicles, so their applicable laws are incomplete. Therefore, it is difficult to enlarge the use range of such electromobiles and promote them. As a result, Measure 25 has a lower target completion rate.

\section{c) Future guidelines}

By now, measures adopted by Yokohama City have received both domestic and international evaluation. The state also hopes to expand this cause and promote it internationally. But in fact, foreign cities are totally different with Yokohama City in culture, law, environment, technical level and other fields. It is difficult for autonomous cities themselves to promote the cause internationally. Now, no financial aids from the state are provided to "FutureCity" to support its international promotion affairs. Therefore, although the guidelines of "FutureCity" Initiative contain the program of "unified export of the whole city", in current stage, Yokohama City does not implement the above program. Besides, with regard to the effective utilization of sustainable R\&D goals of SDGs, the state also makes requirements on Yokohama City. However, Yokohama City was and is completing the goals of SDGs. As for the feedback of effective utilization of SDGs by autonomous cities, Yokohama City considers that it should be understood from a long-lasting perspective.

\subsection{Investigate the proposal of third parties on the "FutureCity" Initiative}

The investigation result is: as for the vision to promote the "FutureCity" Initiative, especially the way to promote the case of successful measures to overseas countries, there are differences between the expectation of the state (originator of the Initiative) and the actual execution of the Initiative. The state considers that, popularizing and promoting successful cases internationally is helpful for other cities and regions to solve similar problems. But in present stage, with regard to the matter of internationally promoting related measures of "FutureCity", the state neither grasp the actual situation of autonomous cities nor establish related mechanism to support them. 
Therefore, the author suggests that a third party be responsible for the negotiation between the state and 11 selected cities for the "FutureCity" Initiative. The third party should give an objective evaluation on measures of "FutureCity", disclose the contents of these measures and manage the domestic and international implementation situation of the measures. Nowadays, all selected cities as FutureCity has set up targets and indexes, calculated their target completion rates based on the indexes and made evaluations on their measures. However, this is independent evaluation of all these cities. Besides, the objective of the Initiative has nothing with achieving "subdistricts where everyone wants to live"; the completion rate of measures can not reflect citizens' degree of satisfaction. The structure of sustainable urban development does not mean that a single city or agency adopts independent measures. The structure cannot be realized if lacking joint effort and cooperation between superior-subordinate governments or all forces both within and without a region, (Shimizu2006). Therefore, in order to make evaluation on "FutureCity" closer to reality, there should be a third party to objectively evaluate the rationality of settled targets and indexes and execution of measures and citizens' opinions should also be listened.

Also, it is required to disclose and manage the promotion situation both in Japan and abroad of the measures of "FutureCity" based on the above objective evaluation. The measures of "FutureCity" is taken according to the specific conditions of different regions, thus whether they are applicable should be considered when being promoted to other regions. Especially, foreign cultures, environment, laws and financial situations are different with those in Japan, so it is difficult for autonomous cities to make judgement. There should be related agencies to provide consultation service when promoting successful cases or the whole program of the "FutureCity" to other regions. To sum up, in order to reach the target of the "FutureCity" Initiative, i.e. stimulating Japanese vitality and realizing internationalized expansion of urban policies, the author suggests that a third-party organization be established to evaluate the measures of FutureCity as well as information disclosure and management when the measures are promoted to overseas countries. Thus, successful cases of "FutureCity" can be expected to provide model solutions to other regions which have environmental and the aging problems. Especially for foreign cities which will also face the same problems with Japan, by adopting the aforesaid suggestions can these cities get successful cases in the form of solution modes.

\section{Conclusion}

The author conducted a research on the "FutureCity" Initiative, guidelines of the state (originator of the Initiative) and the actual execution situation of autonomous cities (executors of the Initiative), taking Yokohama City of Kanagawa Prefecture as example, and clarified the actual situation of the Initiative and the execution situation of related measures. In future, the author will further investigate other selected cities or urban policies of foreign cities and further study whether the Initiative can achieve the expected effect (that is, stimulating domestic vitality and make international contributions). 


\section{References}

[1] FutureCity - EcoModelCity, "FutureCity" Initiative, http://future-city.jp/ (accessed February 4, 2018).

[2] Local Innovative Promotion Affairs Bureau of the Cabinet, Outline of the System of FutureCity Environment Model City SDGs Future City, https://www.kantei.go.jp/jp/singi/tiiki/kankyo/pdf/kankyo_gaiyo.pdf (accessed February 4, 2018).

[3] The prime minister's official residence, (2010), New Growth Strategy - A Play on the Rebirth of Vigorous Japan, (June 18, 2010)

[4] Imai K, (2014), Characteristics and issues of Japanese Promotion of Ecocity, East Asian Perspective of Asian Growth Research Institute, June Issue, pp14.

[5] Keisuke M-Nagano A, (2015), Comprehensive Plan of Appraisal from the Perspective of Sustainable Development, Symposia G (Environment) of Japan Society of Civil Engineers,Vol.71, No.6 (Symposia on Environment System Research), II 273_ II 278.

[6] Takahashi C Uto M Inoue T Matsuoka M Mizuishi T, Urban Export Business (I), Overseas Investment of Urban Infrastructure Construction, Creation of Intellectual Property of Nomura Research Institute, December 2010, pp49-59.

[7] Local Innovative Promotion Affairs Bureau of the Cabinet, FutureCity Environment Model City SDGs Future City, https://wwww.kantei.go.jp/jp/singi/tiiki/kankyo/index.html (accessed February 4, 2018)

[8] Local Innovative Promotion Affairs Bureau of the Cabinet, Medium-term Report on the "FutureCity" Initiative, https://www.kantei.go.jp/jp/singi/tiiki/kankyo/pdf/mirai_concept.pdf, https://www.kantei.go.jp/jp/singi/tiiki/kankyo/pdf/mirai_concept.pdf

(accessed February 4, 2018)

[9] United Nations Population Fund and HelpAge International, 2012, Ageing in the Twenty-First Century A celebration and a Challenge

[10] Public Data of the 7th International Forum on the "FutureCity" Initiative.

[11] Ministry of Foreign Affairs of Japan, SDGs (Sustainable Development Goals), Focus on 2030 for Sustainable Development (PDF), http://www.mofa.go.jp/mofaj/gaiko/oda/files/000270588.pdf

[12] United Nations Publicity Center, Sustainable Development, 2030 Agenda, SDGs logo (accessed February 4, 2018) http://www.unic.or.jp/activities/economic_social_development/sustainable_development/ 2030agenda/ (accessed February 4, 2018)

[13] Yokohama City, (2012), FutureCity Initiative for Yokohama City - OPEN YOKOHAMA, Integration of Personnel, Objects and Affairs, Creating a "Port" leading the trend and value of times.

[14] Yokohama City, Coordinating Head Office of Global Warming, (2016), Urban Construction of the FutureCity - Yokohama City.

[15] Population Statistics Portal Website of Yokohama City, http://www.city.yokohama.lg.jp/ex/stat/

[16] Shimizu M Ueta K, (2006), Current Situation and Problems of the Theory of Sustainable Cities, Official Newspaper of Environmental Science Association, 19 (6), pp595-605.

[17] Takahashi K, (2017), "Sustainable Development Goals (SDGs)" Analysis on Urban Image - for the Research on Problems of the 11 Selected Cities, Information Exchange Research, 2017, No.17, pp73-86. 